\title{
The Rational Distribution of Teaching Resources in Colleges_—Course Arrangement
}

\author{
Jishan $\mathrm{Ma}^{1}$ \& Yanyu Zhang ${ }^{1}$ \\ ${ }^{1}$ Finance Department of International Business School, Jinan University, Zhuhai, China \\ Correspondence: Yanyu Zhang, Jinan University, No. 206, Qianshan Road, Xiangzhou District, Zhuhai, China. \\ Tel: 86-158-2058-0297. E-mail: 1712218208@qq.com
}

Received: June 8, 2017

Accepted: June 23, 2017

Online Published: July 11, 2017

doi:10.5539/emr.v6n2p16

URL: http://doi.org/10.5539/emr.v6n2p16

\begin{abstract}
Under the stimulus of national policy vigorously, the higher education obtained the rapid development. Due to the dramatic increase of students, the slow growth of teaching hardware facilities and the shortage of teacher resources, how to make use of limited resources to meet the teaching demand in the optimal form becomes a problem that needed to be solved at present. Schedule arrangement is a process full of conflicts, because there are so many limitations for teaching resources allocation such as the class time of open courses, the classes, class locations and class teachers' factors such as. In order to improve the efficiency of running school and complete the teaching mission better, it shall use modern information technology in time and space must as far as possible to distribute the teaching resources reasonably. With the aid of optimization theory firstly, this paper establishes a preliminary scheduling optimization model based on the hard constraint conditions to make the needed number for the classroom least as far as possible. Then, we add the soft constraint conditions to the preliminary model and obtain the final optimization model. Finally, this paper adopts the way of comprehensive evaluation, constructs the index system by calculating the classroom utilization, class strength of course object, the dissatisfaction rate of soft constraint conditions, and gets the score standard of curriculum arrangement scheme. For the optimization model of this article, we are using genetic algorithm to solve the results. This paper also gives the calculation steps of genetic algorithm based on course arrangement.
\end{abstract}

Keywords: genetic algorithm, optimization model, comprehensive evaluation

\section{Introduction}

Course arrangement is a very important and difficult problem in the teaching process. With the continuous increase of school enrollments, shortage of teaching resources, how to use the limited teaching resources, to integrate the space and time to make reasonable course arrangement, is now a very focus problem on education in colleges.

In the 1950s, foreign researches on course arrangement were made. In 1963, the mathematical model based on course arrangement has already been proposed in C.C.G otlieb's article, but the model couldn't practice well in reality because the course arrangement had the vulnerable influence on actual problems. In 1976 Bondy regarded a simple course arrangement problem as the dyeing problem of a picture and proposed an algorithm for scheduling problems. In the same year, S.E ven proved that the problem of the curriculum was NP complete, showing that the curriculum table had its own mathematical model, which had the solution and the solution could be found. In 2003, N.N.G libovets and S.A. Medvid analyzed the genetic algorithm on course arrangement in general. In 2007, Radomir Perzina was using genetic algorithms to solve college class problems. For course arrangement problem, foreign researchers never give up and have worked out the curriculum arrangement algorithm, mainly including genetic algorithm and annealing algorithm, greedy algorithm, the hybrid intelligent algorithm, neural network, the hybrid optimization algorithm of course arranging and so on.

Domestic researches on course arrangement are later, which begins in the early 1980s. In 1994, Huang Diming and Liu Qiongxin proposed the mathematical model of the university class scheduling problem and the scheduling algorithm, and discussed the design idea of the algorithm. In 1998, Dong Yanyun, Qian Xiaoqun and Zhang Yushu proposed a computer algorithms of course arrangement based on the analysis of the basic principle and fuzzy principle, the core of which is to calculate RCU and time-classroom slice candidates. In $2006, \mathrm{Pu}$ Baoxing turned the course arrangement problem into an optimization problem, and puts forward "the dynamic 
scaling approach of penalty weight" and "the blocked genetic method". In the same year, Tang Hongying and Zhou Min put forward the idea of stratification. In 2007, Liao Yuan was able to solve university course arrangement problems by using a three-dimensional adaptive genetic algorithm, which was not intuitive and the time complexity is higher. In 2009, Wang Feng, Lin Jie made use of the edge coloring theory of graph theory, modeling of arranging resources, and put forward the more effective polynomial time algorithm, making the solution of the problem more reasonable and humanization.

\section{Model}

\subsection{Model Preparation}

\subsubsection{Model Assumption}

Based on the actual teaching requirements in China, the following assumptions on course arrangement must be made firstly, including:

1) Each semester has 18 weeks to arrange the teaching task;

2) Every school week is scheduled only Monday through Friday;

3) Every school day is divided into two periods in the morning (period 1 and period 2), two in the afternoon (period 3 and period 4), one in the evening (period 5), and each period includes 2 hours to arrange for the same course;

4) The contextual relationship between the course content of different classes in the same class is not considered.

\subsubsection{Model Constraint Conditions}

\section{(1) Hard constraint conditions}

Hard constraint conditions refers to the conditions that must be restricted when solving course arrangement problem. In order to work out the minimum number of all kinds of the required classrooms, we shall first determine the course arrangement situation of different class objects. To determine the course arrangement, the following aspects must be satisfied:

- The same class object cannot take two (or more) course at the same time;

- The same teacher can only teach one course at the same time;

- A classroom can only be arranged one course at the same time;

- The classroom capacity is not less than the actual number of students in class;

- Weekly course arrangement situation shall satisfy the weekly class time of school curriculum;

- All courses should be completed under the requirement of this semester.

In order to fix the schedule and arrange course reasonably, there are some conditions still must be satisfied:

- The class time of every course is fixed;

- Every course is taken continuously and cannot be interrupted until the course is completed.

(2) Soft constraint conditions

The soft constraint conditions are the requirements that shall be satisfied in course arrangement as far as possible, but it is also acceptable if they cannot be satisfied. The common soft constraint conditions in China class includes:

- The compulsory courses are arranged less as far as possible in the time period 4 and 5;

- The courses that do not take up the classrooms are arranged less as far as possible in time period 1 and 5;

- The courses are less arranged as far as possible in time period 4 and 5 of every Friday.

2.1.3 Class Classification and Classroom Classification

(1) Class classification

To construct the model more conveniently, the article divides all the course into three kinds: unoccupied-classroom course, occupied-classroom course, occupied-computer room course, the number of which is respectively $x, y$, and $z(x>0, y>0, z>0)$. This is the most basic classification of course in colleges teaching resource in China. 


\section{(2) Classroom classification}

According to the size of classroom, this paper divided classrooms into three scales: large, medium and small, represented by A, B, C respectively, the capacity of which is respectively a, b, c $(0<\mathrm{a}<\mathrm{b}<\mathrm{c})$. So without considering the utilization ratio of the classroom, when the actual number of students is not more than a, you can use all kinds of classrooms, and when the actual number is greater than a and less than $b$, you can use classroom $\mathrm{A}$ or $\mathrm{B}$, but when actual number is greater than $\mathrm{b}$ you can only use classroom A (the class number of every course is less than the capacity of classroom $\mathrm{C}$ and so does the computer rooms). The details are expressed in Table 1 and Table 2.

Table 1. Classification of available classrooms

\begin{tabular}{cc}
\hline The actual number of taking course & The kinds of available classrooms \\
\hline$n \leq \mathrm{a}$ & A B C \\
$\mathrm{a}<n \leq \mathrm{b}$ & B C \\
$n>\mathrm{b}$ & $\mathrm{C}$ \\
\hline
\end{tabular}

Table 2. Classification of available computer rooms

\begin{tabular}{cc}
\hline The actual number of taking course $n$ & The kinds of available computer rooms \\
\hline$n \leq \mathrm{d}$ & D E F \\
$\mathrm{d}<n \leq \mathrm{e}$ & $\mathrm{E} \mathrm{F}$ \\
$n>\mathrm{e}$ & $\mathrm{F}$ \\
\hline
\end{tabular}

\subsection{Model Construction}

\subsubsection{Construction of a Collection of Parameters}

To simplified the model for convenient operation, this article puts unoccupied-classroom course, occupied-classroom course, occupied-computer room course in order and set up the course number $i$, getting the following results (the same course can have different teachers and course objects, the paper considers this situations different courses $i$ ):

$$
i \in \begin{cases}\{1,2, \ldots, \mathrm{x}\} & \text { unoccupied-classroom courses } \\ \{\mathrm{x}+1, \mathrm{x}+2, \ldots, \mathrm{y}\} & \text { occupied-classroom courses } \\ \{\mathrm{y}+1, \mathrm{y}+2, \ldots, \mathrm{z}\} & \text { occupied-computer room courses }\end{cases}
$$

Defined $L_{i}$ as the collection of parameters of course $i$, and when $L_{\mathrm{s}}=L_{\mathrm{r}}, \mathrm{S}=\mathrm{r}$, so

$$
L_{i}=\left\{W_{i}, h_{i}, \mathrm{t}_{i j}, m_{i k}, Q_{i}, P_{i}, n_{i}, X_{i}\right\}
$$

In the above formula, ${ }^{W_{i}}$ represents the number of class weeks, namely the ratio of the total class hours and class hours per week, which is taken back to integer when the decimal is present (for example, when the total class hours is 40 and week class hours is 3 , this course's average number of class weeks is $40 / 3=13.33333$, so $\left.W_{i}=14\right) ; h_{i}$ represents the week class hours; ${ }^{t}{ }$ represents the $0-1$ variable of the class period of course $i$ : 


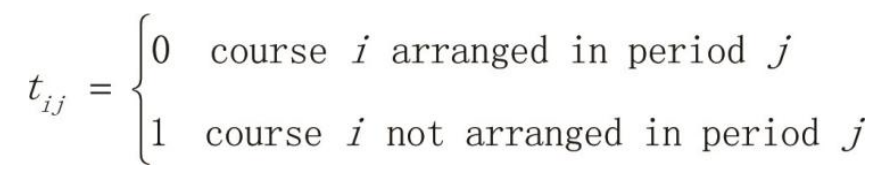

Every teaching week is arranged courses from Monday to Friday, so there are 5 class periods, namely

$$
j=1,2, \ldots, 25
$$

represents the $0-1$ variables of class situation of course $i$ in 18 weeks:

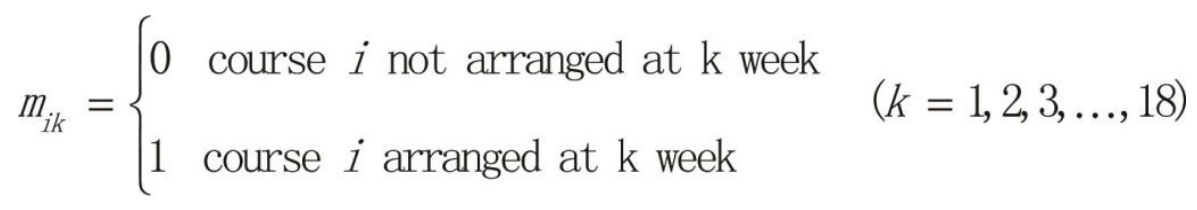

$\mathrm{Q}_{i}$ represents the collection of class objects of course $i$, namely

$$
Q_{i}=\left\{q_{1}, q_{2}, \cdots, q_{n}\right\}
$$

In the formula, $q_{1}, q_{2}, \cdots, q_{n}$ represents the classes that take lessons together; $P_{i}$ represents the collection of teachers of course $i$, and because one lesson is arranged one teacher for the same class object, when other indexes of $L_{i}$ are determined, the teacher of course $i$ is just determined only; $n_{i}$ represents the actual number of class students of course $i ; X_{i}$ represents the 0-1 variables that whether the course $i$ occupies classroom, and when the course $i$ doesn't occupy classroom, $X_{i}$ equals 0 , otherwise, $X_{i}$ equals 1 , which is expressed by

$$
X_{i}= \begin{cases}0 & (i=1,2, \ldots, \mathrm{x}) \\ 1 & (i=\mathrm{x}+1, \mathrm{x}+2, \ldots, \mathrm{z})\end{cases}
$$

\subsubsection{Optimization Model of Course Arrangement}

A constraint equation is constructed according to the hard constraint conditions:

1) Course weeks: the sum of the 0-1 variable $m_{i k}$ of class situation in 18 class weeks of course $i$ shall equal the course week $W_{i}$, namely

$$
\sum_{k=1}^{18} m_{i k}=W_{i}
$$

In the formula, $m_{i k}$ represents the $0-1$ variable, expressing whether course $i$ is arranged at k week. 
2) Weekly class hour: the sum of the $0-1$ variable $t_{i j}$ of weekly class period of course $i$ shall satisfy the required class hours, and every period contains 2 class hours. When the weekly class hour $h_{i}$ is a odd number, it still needs occupying $\left(h_{i}+1\right) / 2$ periods. Let

$$
\mathrm{H}_{i}= \begin{cases}h_{i} & h_{i} \text { is an even number } \\ h_{i}+1 & h_{\text {is an odd number }}\end{cases}
$$

and then

$$
2 \sum_{j=1}^{25} t_{i j}=H_{i}
$$

$t_{i j}$ is a $0-1$ variable, expressing whether course $i$ is arranged at $\mathrm{j}$ period.

\subsubsection{Restrictions of Course Teachers and Class Objects}

The same class object cannot take two (or more) course at the same time and the same teacher can only teach one course at the same time, so for $\forall \mathrm{u}, \mathrm{v} \in\{1,2, \cdots, \mathrm{z}\}$, when $Q_{\mathrm{u}} \cap Q_{\mathrm{v}} \neq \varnothing, P_{\mathrm{u}} \cap P_{\mathrm{v}} \neq \varnothing$, we can get

$$
m_{\mathrm{u} k} t_{\mathrm{v} j}+m_{\mathrm{u} k} t_{\mathrm{v} j} \leq 1 \quad(k=1,2, \ldots, 18 \quad j=1,2, \ldots, 25)
$$

In the formula, $Q_{i}$ represents the collection of class objects of course $i$ and $P_{i}$ represents the collection of class teachers of course $i$.

3) Course continuity: in order to determine the schedule and arrange courses reasonably, we fix the weekly class period of course $i$ is $t_{i j}$ constantly, and every course is taken continuously and cannot be interrupted until the course is completed. So

$$
m_{i k}=m_{i(k+1)}=\cdots=m_{i\left(k+W_{i}-1\right)}
$$

The final intention of course arrangement should aim at the minimum number of all kinds of classrooms required, and the same class can be occupied by different classes at different times when the actual number of class students does not exceed the classroom capacity.

Without considering the utilization of classrooms, because the actual number of class students of all courses is not more than $\mathrm{C}$ classrooms (F computer rooms), the capacity of which is $\mathrm{c}$ (f). When all the classrooms (including the room) reach the maximum capacity, namely $\mathrm{C}$ classrooms ( $\mathrm{F}$ computer rooms), the courses with different class numbers can be arranged in the same idle classroom at different times, and the situation that the class number is beyond the capacity of the classroom will not appear. Therefore, now the need number for classrooms (including the computer rooms) is the least number. 
Since the classrooms can be reused at different times every day, so we just work out the number of classrooms (including the computer rooms) occupied at the periods that needs classrooms mostly, which is the minimum number of classrooms required for this semester. Let it be the $\mathrm{Z}$, as $\min \mathrm{Z}$ is the objective function

$$
\min Z=\max \sum_{i=1}^{\mathrm{z}} X_{i} m_{i k} t_{i j} \quad(k=1,2, \cdots, 18 \quad j=1,2, \cdots, 25)
$$

In the formula, $\mathrm{X}_{\mathrm{i}}$ is a $0-1$ variable, representing that whether course $i$ needs to occupy classrooms; $\mathrm{m}_{\mathrm{ik}}$ represents the 0-1 variable, expressing whether course $i$ is arranged at k week. $\mathrm{t}_{\mathrm{ij}}$ is a $0-1$ variable, expressing whether course $i$ is arranged at $\mathrm{j}$ period.

According to the above analysis, we can get the optimization model of course arrangement:

$$
\begin{aligned}
& \min Z=\max \sum_{i=1}^{\mathrm{z}} X_{i} m_{i k} t_{i j} \\
& \text { s.t. }\left\{\begin{array}{l}
2 \sum_{j=1}^{25} t_{i j}=H_{i} \quad(i=1,2, \cdots ; \mathrm{z}) \\
\sum_{k=1}^{18} m_{i k}=W_{i} \quad(i=1,2 \cdots ; \mathrm{z}) \\
m_{i k} t_{\mathrm{v} j}+m_{i k} t_{\mathrm{v} j} \leq 1 \quad(Q \mathrm{u} \cap Q \mathrm{v} \\
m_{i k}=m_{i(\mathrm{k}+1)}=\cdots=m_{\left(\mathrm{k}+W_{i}-1\right)}
\end{array}\right.
\end{aligned}
$$

\subsubsection{Classroom Arrangement Model}

The classroom (room) obtained in the optimization model is C classrooms (F computer rooms). In order to use the appropriate capacity of the classroom, according to the results of the course arrangement, the classrooms shall be distributed in accordance with the actual number of class students. According to the principle of class classification, we define that $U_{1}$ is the collection of available classroom A, B, C, $U_{2}$ is the collection of available classroom B, C, and $U_{3}$ is the collection of available classroom C. Similarly, $V_{1}$ represents the collection of available classroom D, E, F; $V_{2}$ represents the collection of available classroom E, F; $V_{3}$ represents the collection of available classroom F. So 


$$
\begin{aligned}
& i \in \begin{cases}U_{1} & n_{i} \leq \mathrm{a} \\
U_{2} & \mathrm{a}<n_{i} \leq \mathrm{b} \quad(i=\mathrm{x}+1, \mathrm{x}+2, \ldots, \mathrm{y}) \\
U_{3} & \mathrm{~b}<n_{i} \leq \mathrm{c}\end{cases} \\
& i \in \begin{cases}V_{1} & n_{i} \leq \mathrm{d} \\
V_{2} & \mathrm{~d}<n_{i} \leq \mathrm{e} \quad(\mathrm{i}=\mathrm{y}+1, \mathrm{y}+2, \ldots, \mathrm{z}) \\
V_{3} & \mathrm{e}<n_{i} \leq \mathrm{f}\end{cases}
\end{aligned}
$$

As the classrooms can be reused every day at different times, so we just respectively work out the number of all kinds of classrooms (including the computer rooms) occupied at the periods that needs classrooms mostly, which is the minimum number of all kinds of classrooms required for this semester. Create the following objective functions separately:

$$
\begin{gathered}
S_{1}=\max \sum_{i \in U_{1} \cup U_{2} \cup U_{3}} m_{i k} t_{i j} \\
S_{2}=\max \sum_{i \in U_{2} \cup U_{3}} m_{i k} t_{i j} \\
S_{3}=\max \sum_{i \in U_{3}} m_{i k} t_{i j} \\
(k=1,2, \ldots, 18 \quad j=1,2, \ldots, 25)
\end{gathered}
$$

In the formula, $S_{1}$ represents the minimum of all kinds of required classrooms; $S_{2}$ represents the minimum of together classrooms B and classrooms C; $S_{3}$ represents the minimum of classrooms C.

When $i \in U_{3}$, he course i only uses the classroom $\mathrm{C}$, so to increase classroom utilization, define the number of classroom $\mathrm{C}$ equal to the minimum number of classrooms $\mathrm{C}$, there are

$$
N_{c}=S_{3}=\max \sum_{i \in U_{3}} m_{i k} t_{i j}
$$

When $i \in U_{2}$, the course $\mathrm{i}$ can use the classroom $\mathrm{B}$ and $\mathrm{C}$, so the minimum of classroom $\mathrm{B}$ required is totally equal to the total number of classroom $\mathrm{B}$ and classroom $\mathrm{C}$ required minus the number of classroom $\mathrm{C}$. In order to increase classroom utilization, define the number of classroom $\mathrm{B}$ as

$$
N_{b}=S_{2}-N_{c}=S_{2}-S_{3}=\max \sum_{i \in U_{2} \cup U_{3}} m_{i k} t_{i j}-\max \sum_{i \in U_{3}} m_{i k} t_{i j}
$$

When $i \in U_{2}$, the course $\mathrm{i}$ can use the classroom $\mathrm{A}, \mathrm{B}$ and $\mathrm{C}$, so the minimum of classroom A required is equal to the total number of classroom $\mathrm{A}, \mathrm{B}$ and $\mathrm{C}$ required minus the number of classroom $\mathrm{B}$ and $\mathrm{C}$ required. So the number of classroom A is

$$
N_{a}=S_{1}-N_{b}-N_{c}=S_{1}-S_{2}=\max \sum_{i \in U_{1} \cup U_{2} \cup U_{3}} m_{i k} t_{i j}-\max \sum_{i \in U_{2} \cup U_{3}} m_{i k} t_{i j}
$$

Similarly, the number of classroom D, E and F respectively is 


$$
\begin{gathered}
N_{d}=\max \sum_{i \in V_{1} \cup V_{2} \cup V_{3}} m_{i k} t_{i j}-N_{e}-N_{f} \\
N_{e}=\max \sum_{i \in V_{2} \cup V_{3}} m_{i k} t_{i j}-N_{f} \\
N_{f}=\max \sum_{i \in V_{3}} m_{i k} t_{i j}
\end{gathered}
$$

\subsubsection{Comprehensive Optimization Model of Course Arrangement}

(1) An extreme situation

In order better to construct the course arrangement model under soft constraint conditions, we firstly add an extreme constraint which requires compulsory courses not to be arranged in the time period 4 and 5 . Now we still have to build a mathematical model that requires the minimum number of classrooms (including the machine room). Due to the introduction of compulsory courses and electives, the $0-1$ variable $r_{i}$ is set to reflect the nature of the course.

$$
r_{i}= \begin{cases}0 & \mathrm{i} \text { is elective course } \\ 1 & \mathrm{i} \text { is compulsory course }\end{cases}
$$

So the collection of parameters $L_{i}$ of course $i$ updates to

$$
L_{i}=\left\{W_{i}, \mathrm{~h}_{i}, \mathrm{t}_{i j}, \mathrm{~m}_{i k}, \mathrm{Q}_{i}, \mathrm{P}_{i}, n_{i}, \mathrm{X}_{i}, \mathrm{r}_{i}\right\}
$$

$j=1,2, \ldots, 25$ represents the total class periods $(5 \times 5)$ from Monday to Friday in every teaching week.

This paper respectively uses $J_{1}, J_{2}, J_{3}, J_{4}, J_{5}$ to express the collection of period 1, 2, 3, 4, 5 in one teaching week, so

$$
\begin{aligned}
& J_{1}=\{1,6,11,16,21\} \\
& J_{2}=\{2,7,12,17,22\} \\
& J_{3}=\{3,8,13,18,23\} \\
& J_{4}=\{4,9,14,19,24\} \\
& J_{5}=\{5,10,15,20,25\}
\end{aligned}
$$

The compulsory courses aren't arranged in period 4 and 5, so

$$
\sum_{k=1}^{18} \sum_{i=1}^{\mathrm{z}} \sum_{j \in J_{4}} r_{i} m_{i k} t_{i j}+\sum_{k=1}^{18} \sum_{i=1}^{\mathrm{z}} \sum_{j \in J_{5}} r_{i} m_{i k} t_{i j}=0
$$


In the formula, $m_{i k}$ represents the 0-1 variable, expressing whether course $i$ is arranged at k week; $r_{i}$ is a

0-1 variable which represents the kinds of course $\mathrm{i}\left(0\right.$ is elective course and 1 is compulsory course); ${ }^{t}{ }_{i j}$ is a

$0-1$ variable, expressing whether course $i$ is arranged at j period.

Combine the hard constraint conditions and the former objective function, we can construct a new optimization model of course arrangement:

$$
\begin{aligned}
& \mathrm{m} \text { in } \mathrm{Z}^{\prime}=\mathrm{m} \text { ax } \sum_{i=1}^{\mathrm{z}} m_{i k} X_{i j} t_{i j} \\
& \text { s.t. }\left\{\begin{array}{l}
2 \sum_{j=1}^{25} t_{i j}=H_{i} \quad(i=1,2, \cdots, \mathrm{z}), \\
\sum_{k=1}^{18} m_{i k}=W_{i} \quad(i=1,2, \cdots, \mathrm{z}), \\
m_{\mathrm{u} k} t_{\mathrm{v} j}+m_{\mathrm{u} k} t_{\mathrm{v} j} \leq 1\left(Q_{\mathrm{u}} \cap Q_{\mathrm{v}}=\varnothing, P_{\mathrm{u}} \cap P_{\mathrm{v}}=\varnothing\right), \\
m_{i k}=m_{i(\mathrm{k}+1)}=\cdots=m_{i\left(\mathrm{k}+W_{i}-1\right)}, \\
\sum_{k=1}^{18} \sum_{i=1}^{\mathrm{z}} \sum_{j \in J_{4}} r_{i} m_{i k} t_{i j}+\sum_{k=1}^{18} \sum_{i=1}^{\mathrm{z}} \sum_{j \in J_{5}} r_{i} m_{i k} t_{i j}=0 .
\end{array}\right.
\end{aligned}
$$

(2) Comprehensive optimization model of course arrangement

Based on the extreme constraint above, we gradually relax constraints and close to the reality, make the compulsory courses arranged less in the time period 4 and 5 and the unoccupied-classroom courses less in the time period 1 and 5 as far as possible, and also arrange courses less in time period 4 and 5 every Friday. In order to satisfy these constraint conditions at the same time, our aim is to make the sum of the number of compulsory courses arranged in time period 4 and 5, the number of unoccupied-classroom course arranged in the time period 1 and 5 and the number of courses arranged in the time period 4 and 5 every Friday minimize. Basing on the previous model, we set the model as follows:

Due to the number of classrooms is fixed, when $i \in U_{3}$, course only use classroom $\mathrm{C}$, and in order to ensure that all courses can use classrooms at the same time, there shall be the minimum of classroom $\mathrm{C}$ required is not beyond $\mathrm{c}$. To enhance the utilization of classrooms, let the number of classroom $\mathrm{C}$ is equal to the minimum of classroom $\mathrm{C}$ required, so

$$
N_{c}=S_{3}=\max \sum_{i \in U_{3}} m_{i k} t_{i j} \leq \mathrm{c}
$$

When $i \in U_{2}$, the course i only uses classroom $\mathrm{B}$ and $\mathrm{C}$, so the minimum of classroom $\mathrm{B}$ required is not over $\mathrm{b}$, namely

$$
N_{b}=S_{2}-N_{c}=S_{2}-S_{3}=\max \sum_{i \in U_{2} \cup U_{3}} m_{i k} t_{i j}-\max \sum_{i \in U_{3}} m_{i k} t_{i j} \leq \mathrm{b}
$$

When $i \in U_{1}$, the course i can use classroom A, B and $\mathrm{C}$, so the minimum of classroom A required is not over a, namely 


$$
N_{a}=S_{1}-N_{b}-N_{c}=S_{1}-S_{2}=\max \sum_{i \in U_{1} \cup U_{2} \cup U_{3}} m_{i k} t_{i j}-\max \sum_{i \in U_{2} \cup U_{3}} m_{i k} t_{i j} \leq \mathrm{a}
$$

Similarly, the constraints of computer rooms D, E and F required are respectively

$$
\begin{gathered}
N_{d}=\max \sum_{i \in V_{1} \cup V_{2} \cup V_{3}} m_{i k} t_{i j}-N_{e}-N_{f} \leq \mathrm{d} \\
N_{e}=\max \sum_{i \in V_{2} \cup V_{3}} m_{i k} t_{i j}-N_{f} \leq \mathrm{e} \\
N_{f}=\max \sum_{i \in V_{3}} m_{i k} t_{i j} \leq \mathrm{f}
\end{gathered}
$$

Combine the hard constraint conditions and the soft constrain conditions, we can obtain the comprehensive objective function:

- The number of compulsory courses arranged in time period 4 and 5 is

$$
y_{1}=\sum_{k=1}^{18} \sum_{i=1}^{\mathrm{z}} \sum_{j \in J_{4}} r_{i} m_{i k} t_{i j}+\sum_{k=1}^{18} \sum_{i=1}^{\mathrm{z}} \sum_{j \in J_{5}} r_{i} m_{i k} t_{i j}
$$

- The number of unoccupied-classroom courses arranged in in time period 1 and 5

$$
y_{2}=\sum_{k=1}^{18} \sum_{i=1}^{\mathrm{z}} \sum_{j \in J_{1}} X_{i} m_{i k} t_{i j}+\sum_{k=1}^{18} \sum_{i=1}^{\mathrm{z}} \sum_{j \in J_{5}} X_{i} m_{i k} t_{i j}
$$

The number of courses arranged in time period 4 and 5 every Friday

$$
y_{3}=\sum_{k=1}^{18} \sum_{i=1}^{\mathrm{z}} \sum_{j \in\{24,25\}} m_{i k} t_{i j}+\sum_{k=1}^{18} \sum_{i=1}^{\mathrm{z}} \sum_{j \in\{24,25\}} m_{i k} t_{i j}
$$

Construct the objection function $Z^{\prime \prime}$ to make the sum of the number of compulsory courses arranged in time period 4 and 5, the number of unoccupied-classroom course arranged in the time period 1 and 5 and the number of courses arranged in the time period 4 and 5 every Friday minimize, namely

$$
\min Z^{\prime \prime}=y_{1}+y_{2}+y_{3}
$$

Combine the all constraints above, we construct the comprehensive optimization model of course arrangement: 


$$
\begin{aligned}
& \min Z^{\prime \prime}=y_{1}+y_{2}+y_{3} \\
& 2 \sum_{j=1}^{25} t_{i j}=H_{i} \quad(i=1,2, \cdots, \mathrm{z}) \\
& \text { s.t. }\left\{\begin{array}{l}
\sum_{k=1}^{8} m_{i k}=W_{i} \quad(i=1,2, \cdots, \mathrm{z}) \\
m_{\mathrm{u} k} t_{\mathrm{v} j}+m_{\mathrm{u} k} t_{\mathrm{vj}} \leq 1\left(Q_{x} \cap Q_{y}=\varnothing, P_{x} \cap P_{y}=\varnothing\right) \\
\left.m_{i k} \leq \mathrm{a}+1\right) \\
N_{b} \leq \mathrm{b} \\
N_{c} \leq \mathrm{c} \\
N_{d} \leq \mathrm{d} \\
N_{e} \leq \mathrm{e} \\
N_{f} \leq \mathrm{f}
\end{array}\right.
\end{aligned}
$$

\subsubsection{Construction of Comprehensive Evaluation Model}

For the comprehensive optimization model of course arrangement under hard and soft constraint conditions, in order to further research, the comprehensive evaluation model is constructed from three aspects, including classroom utilization, class strength of course object, the dissatisfaction rate of soft constraint conditions.

1) Classroom utilization

Construct the index of classroom (including computer rooms) utilization to reflect the occupancy of occupied classroom every class. Due to the different classes take courses in different time periods in every classroom, and for the same class object of one course, there also maybe occupying different classrooms. This paper uses the ratio of the actual number of classes in all the courses and the actual total capacity of all classrooms to express the classroom utilization.

Set the classroom capacity as $S$, so that the capacity of classroom A, B, C and computer room D, E, F are respectively

$$
\begin{aligned}
& S_{a}=\mathrm{a}, S_{b}=\mathrm{b}, S_{c}=\mathrm{c} \\
& S_{d}=\mathrm{d}, S_{e}=\mathrm{e}, S_{f}=\mathrm{f}
\end{aligned}
$$

The utilization of classrooms is

$$
\eta=\frac{\sum_{i=1}^{\mathrm{z}} g_{i} n_{i}}{18 \times 50 \times\left(N_{a} \mathrm{~S}_{a}+N_{b} \mathrm{~S}_{b}+N_{c} S_{c}+N_{d} \mathrm{~S}_{d}+N_{e} \mathrm{~S}_{e}+N_{f} \mathrm{~S}_{f}\right)}
$$

In the formula, $g_{i}$ represents the number of total class hours of course $i, n_{i}$ represents the number of actually taking courses, $N_{a}, N_{b}, N_{c}, N_{d}, N_{e}, N_{f}$ respectively represents the number of classroom A, B, C, D, 
E, F, and the number of total class weeks is 18 every semester, the number of total class hours every week is 50 (every day has 10 class hours from Monday to Friday).

2) Class strength of course object

Construct the class strength of course object, and due to the exist of combined courses, the class objects of one course could include different classes. Take the class as an unit to analyze the strength of class and use $q_{x}$ to represent the class. If any class needs to take course $i$, we can get

$$
q_{x} \in Q_{i}
$$

Among the formula, ${ }_{i}$ is the set of class objects of course ${ }^{i}$. The maximum of class periods every week of class $\mathrm{x}$ is

$$
\mu=\frac{\max \sum_{i} \sum_{j=1}^{25} m_{i k} t_{i j}}{25}
$$

The maximum of class strength every week of class $\mathrm{x}$ is the ratio of the maximum of class periods and the total class periods every week (25).

$$
\max \sum_{i} \sum_{j=1}^{25} m_{i k} t_{i j} \quad\left(q_{x} \in Q_{i}, i=1,2, \ldots, \mathrm{z} \quad \mathrm{k}=1,2, \ldots, 18\right)
$$

3) Dissatisfaction rate of soft constraint conditions

Now we construct the index of dissatisfaction rate according to the soft constraint conditions.

- The number of compulsory courses arranged in time period 4 and 5 is

$$
y_{1}=\sum_{k=1}^{18} \sum_{i=1}^{\mathrm{z}} \sum_{j \in J_{4}} r_{i} m_{i k} t_{i j}+\sum_{k=1}^{18} \sum_{i=1}^{\mathrm{z}} \sum_{j \in J_{5}} r_{i} m_{i k} t_{i j}
$$

- The number of unoccupied-classroom courses arranged in time period 1 and 5 is

$$
y_{2}=\sum_{k=1}^{18} \sum_{i=1}^{\mathrm{z}} \sum_{j \in J_{1}} X_{i} m_{i k} t_{i j}+\sum_{k=1}^{18} \sum_{i=1}^{\mathrm{z}} \sum_{j \in J_{5}} X_{i} m_{i k} t_{i j}
$$

- The number of courses arranged in time period 4 and 5 every Friday is

$$
y_{3}=\sum_{k=1}^{18} \sum_{i=1}^{\mathrm{z}} \sum_{j \in\{24,25\}} m_{i k} t_{i j}+\sum_{k=1}^{18} \sum_{i=1}^{\mathrm{z}} \sum_{j \in\{24,25\}} m_{i k} t_{i j}
$$

- The number of total courses arranged in time period 4 and 5 is

$$
Y_{1}=\sum_{k=1}^{18} \sum_{i=1}^{\mathrm{z}} \sum_{j \in J_{4}} m_{i k} t_{i j}+\sum_{k=1}^{18} \sum_{i=1}^{\mathrm{z}} \sum_{j \in J_{5}} m_{i k} t_{i j}
$$

- The number of total unoccupied-classroom courses arranged in time period 1 and 5 is

$$
Y_{2}=\sum_{k=1}^{18} \sum_{i=1}^{\mathrm{z}} \sum_{j \in J_{1}} m_{i k} t_{i j}+\sum_{k=1}^{18} \sum_{i=1}^{\mathrm{z}} \sum_{j \in J_{5}} m_{i k} t_{i j}
$$


- The number of total courses in this semester is

$$
Y_{3}=\sum_{k=1}^{18} \sum_{i=1}^{\mathrm{z}} \sum_{j=1}^{25} m_{i k} t_{i j}
$$

The proportion of the number of compulsory courses of the number of total courses arranged in time period 4 and 5, the number of unoccupied-classroom courses of the number of total unoccupied-classroom courses arranged in time period 1 and 5, and the number of courses arranged in time period 4 and 5 every Friday of the number of total courses in this semester are respectively.

$$
\begin{gathered}
\beta_{1}=\frac{y_{1}}{Y_{1}} \\
\beta_{2}=\frac{y_{2}}{Y_{2}} \\
\beta_{3}=\frac{y_{3}}{Y_{3}} \\
\theta=\beta_{1}+\beta_{2}+\beta_{3}
\end{gathered}
$$

4) Construction of comprehensive evaluation index

The comprehensive evaluation index is constructed by classroom utilization $\eta$, class strength of course object $\mu$, dissatisfaction rate of soft constraint conditions $\theta$. Because $\eta$ has positive correlation with the course arrangement situation but $\mu$ and $\theta$ have negative correlation with it, we can get the final comprehensive value is

$$
\gamma=\frac{\eta}{(\mu+\theta)}
$$

When $\gamma>0.9$ we say the optimization degree of model is high.

When $0.5 \leq \gamma<0.9$ we say the optimization degree of model is general.

When $\gamma<0.5$ we say the optimization degree of model is low.

\section{Algorithm}

For the optimization models constructed in this paper, we all use genetic algorithm to work out. According to the characteristics of genetic algorithm, the solving steps are as following:

Step 1 (coding): According to the relevant conditions of the course arrangement, a binary encoding is adopted to represent the individual genotype, so the length of the actual gene is the string $\mathrm{z}^{*} 18^{*} 25$. Through the arrangement of two symbols - 0,1 , this string can represent a variety of different course arrangements.

Step 2 (calculating the target function value): The target function is the maximum of classrooms in one time period, namely 


$$
Z=\max \sum_{i=1}^{\mathrm{z}} X_{i} m_{i k} t_{i j}
$$

Step 3 (calculating individual fitness): The individual fitness function is the target function of the model, so directly make individual fitness equal to the target function.

Step 4 (conducting selection and elimination): Make use of the constraint conditions to conduct elimination (Here we use the initial hard constraint conditions):

$$
\text { s.t. }\left\{\begin{array}{l}
2 \sum_{j=1}^{25} t_{i j}=H_{i}(i=1,2, \cdots, \mathrm{z}), \\
\sum_{k=1}^{18} m_{i k}=W_{i}(i=1,2, \cdots, \mathrm{z}), \\
m_{\mathrm{u} k} t_{\mathrm{v} j}+m_{\mathrm{u} k} t_{\mathrm{v} j} \leq 1\left(Q_{\mathrm{u}} \cap Q_{\mathrm{v}}=\varnothing, P_{\mathrm{u}} \cap P_{\mathrm{v}}=\varnothing\right), \\
m_{i k}=m_{i(\mathrm{k}+1)}=\cdots=m_{i\left(\mathrm{k}+W_{i}-1\right)} .
\end{array}\right.
$$

The genotype that fails to meet the above conditions will be eliminated and the suitors will enter the next generation.

Step 5 (individual crossing): Each individual in the group intersected with a certain probability, starting from the third position of each individual to get two new genotypes.

Step 6 (mutation): Each individual gene changes in a certain probability, creating a new gene in the possible planning space.

\section{Model Parameters}

$L_{\mathrm{i}}$ the set of parameters of course $i$

$W_{i}$ the class weeks required of course $i$

$h_{i}$ the weekly class hours of course $i$

$m_{i k}$ the $0-1$ variables of class situation of course $i$ in 18 weeks

$Q_{i}$ the collection of the class objects of course $i$

$P_{i}$ the collection of teachers of course $i$

$t_{i j}$ the $0-1$ variable of the class period of course $i$

$X_{i}$ the 0-1 variablethat whether the course $i$ occupies classroom

$r_{i}$ the $0-1$ variable that reflects the course nature

$J_{1}$ the collection of period 1 in a teaching week

$U_{1}$ the collection of courses which can use classroom A, B and C

$V_{1}$ the collection of courses which can use classroom D, E and $\mathrm{F}$

$N_{a}$ the number of classroom A required

$N_{b}$ the number of classroom B required

$\eta$ the utilization of classrooms

$\mu$ the maximum of weekly class strength

$\theta$ the dissatisfied rate under soft constraint conditions 


\section{Reference}

Aziz, H. Y. (2009). QSAR Study of the 5-HT1A Receptor Affinities of Arylpiperazines Using a Genetic Algorithm-Artificial Neural Network Model. Monatsheftefur Chemie-Chemical Monthly, 2009(5), 523-530.

Retrieved

from https://www.researchgate.net/publication/239130503_QSAR_study_of_the_5HT_1A_receptor_affinities_of arylpiperazines_using_a_genetic_algorithm-artificial_neural_network_model

Boris, P. L., \& Jessica, S. C. (2011). A Deterministic Annular Crossover Genetic Algorithm Optimisation for the Unit Commitment Problem. Expert Systems with Applications, 38(6), 6523-6529. https://doi.org/10.1016/j.eswa.2010.11.089

Carrasco, M. E., \& Pato, M. V. (2004). A Comparison of Discrete and Continuous Neural Network Approaches to Solve the Class/Teacher Timetabling Problem. European Journal of Operational Research, 153(1), 65-79. https://doi.org/10.1016/S0377-2217(03)00099-7

Dong, Y. Y., Qian, X. Q., \& Zhang, Y. S. (1998). An Algorithm of Computer Software for Class Schedule Planning of Universities. Journal of Southwest JiaoTong University. Retrieved from http://www.cnki.com.cn/Article/CJFDTotal-XNJT806.012.htm

Even, S., \& Itai, S. A. (1976). On the Complexity of Timetable and Multicommodity Flow Problems. SLAM Journal on Computing, 691-703. https://doi.org/10.1137/0205048

Glibovets, N. N., \& Medvid, S. A. (2003). Genetic Algorithms Used to Solve Scheduling Problems. Cybernetics and Systems Analysis, 39(1), 81-90. https://doi.org/10.1023/A:1023825226796

Gotlieb, C. C. (1963). The Construction of Class Teacher Time Tables (pp. 73-74). Proceeding IFIP Congress. Retrieved from http://citeseer.uark.edu:8080/citeseerx/showciting;jsessionid=867275380D30F7EB7313D23A102A5953?ci $\mathrm{d}=8001159$

Haiyan, P., Jun, Z., \& Danfu, H. (2003). Genetic Algorithms Applied to Multi-Class Clustering for Gene Expression Data. Genomics, Proteomics \& Bioinformatics, 1(4). Retrieved from http://www.cqvip.com/Main/Detail.aspx?id=12233416

Holland, J. H. (1992). Adaptation in Natural and Artificial Systems: An Intro-ductory Analysis with Applications to Biology, Control, and Artificial Intelligence (2nd ed.). Cambridge: MIT Press. Retrieved from https://www.amazon.com/exec/obidos/ASIN/0262581116/categoricalgeome

Huang, D., \& Liu, Q. (1994). The Algorithm Design and Implementation of Arranging School Timetable in University. Journal of UEST of China. Retrieved from http://www.cqvip.com/QK/90838X/1994S1/4001438901.html

Koumousis, V. K., \& Katsaras, C. P. (2006). A Saw-tooth Genetic Algorithm Combining the Effects of Variable Population Size and Reinitialization to Enhance Performance. Evolutionary Computation, 10(1), 19-28. https://doi.org/10.1109/TEVC.2005.860765

Liao, Y. (2007). Application of Adaptive Genetic Algorithm Based on 3D Coding in Course Arrangement System. Nanchang University. Retrieved from http://d.wanfangdata.com.cn/Thesis/Y1152111

Lin, Y. C., Hwang, K. S., \& Wang, F. S. (2004). A Mixed-codingscheme of Evolutionary Algorithms to Solve Mixed-integer Nonlinear Programming Problems. Computers and Mathematics with Ap-plications, 47(8-9), 1295-1307. https://doi.org/10.1016/S0898-1221(04)90123-X

Mithilesh, K., \& Chandan, G. (2017). The elitist non-dominated sorting genetic algorithm with inheritance (i-NSGA-II) and its jumping gene adaptations for multi-objective optimization. Information Sciences, 382-383. Retrieved from http://www.sciencedirect.com/science/article/pii/S0020025516319223

Perzina, R. (2007). Solving the University Timetabling Problem with Optimized Enrollment of Students by a Self-adaptive Genetic Algorithm. Practice and Theory of Automated Timetabling VI, 3867, 248-263. https://doi.org/10.1007/978-3-540-77345-0_16

$\mathrm{Pu}$, B. X. (2006). The Algorithm of Arranging School Timetable based on Genetic Algorithms. Journal of the CUN (Natural Sciences Edition). Retrieved from http://www.cqvip.com/Main/Detail.aspx?id=21277897

Wang, F., \& Lin, J. (2009). Graphic Model and Algorithm of Course Scheduling Problem in Colleges. Computer Engineering and Applications, 45(27). Retrieved from http://d.wanfangdata.com.cn/Periodical/jsjgcyyy200927072 


\section{Copyrights}

Copyright for this article is retained by the author(s), with first publication rights granted to the journal.

This is an open-access article distributed under the terms and conditions of the Creative Commons Attribution license (http://creativecommons.org/licenses/by/4.0/). 